\title{
Vibration Analysis of Frame Structure with
}

\section{Soil-Structure Interaction}

\author{
Rafi Mohammed Qasim \\ Department of Environment and Pollution Engineering, College of Engineering Technical, University of Southern Technical, Basrah \\ 00964, Iraq
}

\begin{abstract}
A common design practice for dynamic loading assumes the frame fixed at their bases. In reality, the supporting soil medium allows movement to some extent due to its property to deform. This may decrease the overall stiffness of the structural system and may increase the natural period of the system. The effect of soil flexibility is suggested to be accounted through consideration of springs which have specified stiffness and soil half space. Results show that the dynamic response of frame structure to vibrations is due to applied dynamic load and is highly dependent on the soil type and the method of modeling soil structure interaction. The response of frame structure under dynamic load is higher in case of linear discrete independent spring as comparing with perfect bond cases. Except the response of frame in case of piles embedded in soft clay, half space are higher than frame with piles and linear elastic spring due to the interaction between the frequencies of applied load and frequencies of frame structure. Also, result showed that it is important to include the soil-structure interaction in the analysis of the system in order to correctly simulate the dynamic problem for controlling on the resonance phenomena.
\end{abstract}

Key words: Soil structure interaction, flexibility, pile.

\section{Introduction}

The framed structures are normally analyzed with their bases considered to be either completely rigid or hinged. However, the foundation resting on deformable soils also undergoes deformation depending on the relative rigidities of the foundation superstructure and soil. Therefore, interactive analysis is necessary for the accurate assessment of the response of the superstructure [1]. The response of structure foundation system subject to static and dynamic load is influenced significantly by the behavior of contact junctions between the structural element and the surrounding soil enclosed them. These junctions represent the interface between the response of the soil-structure which transmit the load and the deformations which is called soil-structure interaction [2]. Analytic and numerical models for dynamic analysis typically ignore soil-structure

Corresponding author: Rafi Mohammed Qasim, M.Sc., research field: civil engineering. E-mail: Abd.luaay@yahoo.com. interaction (SSI) effects of the coupled in nature structure-foundation-soil system. It has been recognized that SSI effects may have a significant impact especially on cases involving heavier structures and soft soil condition [3]. Various researchers suggest that interaction is not significant unless it increases the fundamental period by at least $25 \%$ [4]. The dynamic analysis consists of two parts [5]:

- Free vibration analysis: This type of analysis uses to find the natural frequencies of the mode shapes that the structure undergoes, which due to the motion by some disturbance at initial time equal to zero and after that, no external dynamic force is applied. The determination of the structures natural frequencies is very useful to avoid the increasing of structures dynamic response due to resonance phenomena;

- Forced vibration: The forced vibration analysis uses to determine the dynamic response of the structure such as the time-varying displacement, stresses and forces when the structure subjected to 
external dynamic force. The dynamic excitation that may be applied on the structures can be classified into two types [6]: The first is the direct excitations where the load is applied directly on the structures; The second type is the indirect excitations where the load is transmitted to the structures through the soil in the form of stress waves. These waves emanate from source of dynamic excitation and spread through the soil then impinge the structures. In general, the dynamic analysis of structural systems is a direct extension of static analysis [7].

\section{Modeling and Mathematical Formulation}

The finite element method is one of the numerical techniques that can be used to obtain theoretical analysis of these types of problems. In the finite element method, the actual continuum is represented as an assemblage of subdivision called elements. These elements are considered to be interconnected at specified joints called nodes or nodal points. The nodes usually lie on the element boundaries where adjacent elements are considered to be connected. Since the actual variation of the field variable (displacement, stress, temperature, pressure or velocity) inside the continuum is not known, it can be assume that the variation of the field variable inside a finite element can be approximated by a simple function. These approximation functions (also called interpolation models or shape function) are defined in terms of the values of the field variables at the nodes [8]. ANSYS system is a finite elements program. This program contains several types of elements which can be used to formulate the structural problems. In the present study, three different types of elements are used. The first type of the elements is the Beam 3D elastic 4 element with tension, compression, torsion and bending capabilities. The element has six degrees of freedom at each node, translation in nodal $\mathrm{x}, \mathrm{y}$ and $\mathrm{z}$, directions and rotations about nodal $\mathrm{x}, \mathrm{y}$ and $\mathrm{z}$ axes. This element is used to represent beam, column, pile cap and piles. The second type of elements is the combination of spring-damper 14 elements with longitudinal capability. The longitudinal spring-damper option is a uniaxial tension-compression element with up to three degrees of freedom at each node: translation in the nodal $\mathrm{x}, \mathrm{y}$ and $\mathrm{z}$ directions. No bending or torsion is considered and the spring or damping capability may be removed from the element. In the present study, the element used to represent the sub-grade spring coefficient (stiffness of equivalent soil spring). The third type of elements is the SOLID45 element which is an eight-node cubic element with large deflection and large strain capabilities. The element has three degrees of freedom at each node: translation in the nodal $\mathrm{x}, \mathrm{y}$ and $z$ directions. This element is used to simulate soil. The finite element modeling can be performed in two or three dimensions. It is realized that for problems, they have great variations in the geometric and material properties of the soil-structure system. Furthermore, a full three dimensions finite element modeling may still be necessary in order to capture some of the local effects that may be hidden by two dimensional or other simplified models [9]. In the present study, the three dimension finite element modeling is used.

\section{Problem Definition}

This search includes numerical application to study the vibration analysis of frame structure under harmonic load. By using finite element method, the whole system is meshed to small element. The software Ansys12 program is used to perform the dynamic analysis of the cases studied. Two types of analysis are included in this study. The first is the free vibration which is performed by Block Lanczos iteration method to determine the natural frequencies and their mode shapes. The second type is the forced vibration analysis which is performed in frequency domain where the inputs are the amplitude and frequency of dynamic load and the output is the displacement. The Sparse Solver technique is used to 
solve the global matrix of forced vibration equation and determine the dynamic response (displacement) of frame structure. Description of the case study: The whole system is divided into two part frame structures which consist of beam, column, pile cap, piles and soil. All parts are formulated by finite element method. The description of each part and the dynamics loads are as follow. Frame description: The frame considered with one bay three stories with beam size $(0.5 \times 0.5) \mathrm{m}$, column size $(0.5 \times 0.5) \mathrm{m}$, story height equal to $3.5 \mathrm{~m}$, each bay of dimension $(5 \times 5) \mathrm{m}$ and four pile caps of $(1 \times 1) \mathrm{m}$. The pile caps have the dimension of $(1 \times 1$ $\times 1) \mathrm{m}$. The used piles have length equal to $12 \mathrm{~m}$ with cross section $(0.5 \times 0.5)$ meter square concrete pile. Materials of frame structure with foundation assumed to behave as linear elastic. A structural damping of $(\zeta$ $=0.02$ ) is assumed. Properties of concrete used for constructing the frame structure with foundation are as follows: The elasticity modulus of concrete $(\mathrm{Ec})$ is equal to $29,725 \mathrm{MPa}$ which is calculated from the following equation (based on the ACI318-08 formula for normal-weight concrete) $\left(\mathrm{Ec}=4,700 \sqrt{f_{c}^{\prime}}\right)$. Where, $f_{c}^{\prime}$ is the cylinder ultimate compression strength of concrete which is assumed equal to $40 \mathrm{Mpa}$ in this study; The concrete density ( $\rho$ ) is assumed equal to $2,400 \mathrm{Kg} / \mathrm{m}^{3}$; Poissons ratio of concrete is assumed to be 0.2. Another factor studied in this search is the frame base fixation to evaluate the effect of this factor. The frame is analysed for three different base conditions as follows: Firstly, the base of the frame is completely fixed; Secondly, each leg of the frame is supported by a pile. The pile is divided into number of space frame elements on winkler foundation. But in this case (first condition), the spring stiffness in the horizontal directs are calculated from the normal modulus of sub-grade reaction that is given by the Eq. (1) $[10]$ :

$$
K_{n}=\frac{E_{S}}{d\left(1-\mu_{s}^{2}\right)}
$$

Where, $\mathrm{E}_{\mathrm{s}}$ : soil modulus of elasticity; S: poison's ratio; $d$ : pile diameter.
For the case (second condition), the coefficient of lateral sub-grade reaction (the modulus of subgrade reaction) $k_{s}$ is related to $\mathrm{E}_{\mathrm{s}}$ in Eq. (2) [11]:

$$
k_{S}=\frac{0.48 \text { to } 0.9 \mathrm{Es}}{B}
$$

Where, B: pile diameter and 0.9 for round pile.

For the case (third condition), the coefficient of lateral sub-grade reaction (the modulus of subgrade reaction) $k_{s}$ is related to $\mathrm{E}_{\mathrm{s}}$ in Eq. (3) [11]:

$$
k_{S}=\frac{1.8 \mathrm{Es}}{B}
$$

Where, B: pile diameter.

For the case (fourth condition), the coefficient of lateral sub-grade reaction (for cohesive soils) $k_{s}$ is related to $E_{s}$ in Eq. (4) [11]:

$$
k_{s}=\frac{1.6 \mathrm{Es}}{B}
$$

Where, B: pile diameter.

For the cases (fifth and sixth condition respectively), Eqs. (5) and (6) are proposed for computing the coefficient of horizontal subgrade reaction in buried circular conduits and are employed for evaluation of $k_{S}$ in few limited cases [12]:

$$
\begin{aligned}
& K_{S}=\frac{2 E_{S}}{B\left(1+v_{S}\right)} \\
& K_{S}=\frac{0.65 E_{S}}{B\left(1-v_{S}^{2}\right)}
\end{aligned}
$$

The above six equation are used to calculated the soil stiffness (soil modulus) for soft clay and medium clay. Also for dense sand, the search study five cases and the equations that use in these studied are as in Eqs. (7-11):

$$
\begin{aligned}
& K_{n}=\frac{E_{S}}{d\left(1-\mu_{S}^{2}\right)} \\
& k_{s}=\frac{E s}{B} \\
& k_{S}=\frac{3 \mathrm{Es}}{B} \\
& K_{S}=\frac{2 E_{S}}{B\left(1+v_{S}\right)} \\
& K_{S}=\frac{0.65 E_{S}}{B\left(1-v_{S}^{2}\right)}
\end{aligned}
$$


Effects of the soil surrounding the piles in the horizontal direction were modeled in terms of elements with axial stiffness only. These elements were placed only on one side of the pile with equal axial stiffness in compression and tension. The soil spring stiffness at any depth was obtained according to the relation [13]:

$$
k_{s h}=k_{s} \cdot \Delta_{z} \cdot \mathrm{z}
$$

Where, $k_{s}$ is the coefficient of subgrade reaction; $\Delta_{z}$ is the spacing between the spring at a depth $\mathrm{z}$.

Thirdly, the soil assumed as a half space of a homogenous, isotropic and damped viscoelastic material. The half space of soil is represented by using brick finite elements. The bond between soil and piles are assumed perfect bond. The search study the behavior of frame structure under dynamic load in two different half space sizes: the dimension of first half space is $(15 \times 15 \times 12) \mathrm{m}$ while the dimension of second half space is $(25 \times 25 \times 15) \mathrm{m}$. Fixed boundary conditions are assumed along all external sides of soil half space except the top (ground surface) which is remained free. The bond between soil and piles are assumed perfect bond in all cases. Dynamic load represent a concentrated harmonic load which is applied laterally at the joints of frame the position of this joints at first, second and third story respectively. The amplitude of the harmonic load is equal to $5 \mathrm{KN}$ in the positive direction for all cases. Different load frequencies are considered within the range of 0.5 to 1.5 of the first natural frequency of the frame structure with fixed boundary condition.

\section{Results and Discussion}

\subsection{Free Vibration Analysis.}

In this part of analysis, the frame structure natural frequencies and their mode shapes for the three cases of base fixations are determined and the resulted natural frequencies are given in Tables 2-13.

Tables 2-13 show the natural frequency and period for the cases of fixed, piles with linear spring and piles have perfect bond with surrounding soil respectively.

Also this part of analysis is performed to predict the effect of the soil surrounding the piles on the natural frequencies and their mode shapes. The natural frequencies and mode shapes are determined for the following cases:

- Determination of the natural frequencies and mode shapes for frame structure only assuming fixed boundary condition;

- Determination of the natural frequencies and mode shapes for the whole system (the frame with foundation and soil for all cases).

Types of soils used in this study are as follows and soil properties are shown in Table 1 and the soil stiffness variation with depth are shown in Figs. 1-3:

- Soft silty clay soil for the whole soil domain;

- Medium silty clay soil for the whole soil domain;

- Dense sand-gravel soil for the whole soil domain.

It is clear that natural frequency of the modes change from case to case and this is due to difference in the number of free degrees of freedom in the cases. Also, Tables 2-13 show that the period of the first mode in the case of frame supported by piles with linear spring equal to 5.89 , the period of the frame with a fixed base and the same result are obtained for all causes (six cases for soft clay, six cases for medium clay and five cases for dense gravel) when soil are replaced by linear discrete independent spring. This comparative are based on the first natural period only. In the case of perfect bond between piles and

Table 1 Properties of each soil.

\begin{tabular}{|c|c|c|c|c|}
\hline Type of soil & $\begin{array}{l}\text { Modulus of } \\
\text { (Es) (map) }\end{array}$ & $\begin{array}{c}\text { elasticity Density }\left(\left(\rho_{s}\right)\right. \\
\left(\mathrm{kg} / \mathrm{m}^{3}\right)\end{array}$ & Poison's ratio $\left(v_{\mathrm{s}}\right)$ & Damping ratio $\left(\zeta_{s}\right)$ \\
\hline Soft clay & 48 & 1,600 & 0.4 & 0.02 \\
\hline Medium clay & 98 & 1,900 & 0.4 & 0.02 \\
\hline Dense sand & 182 & 2,200 & 0.3 & 0.02 \\
\hline
\end{tabular}


Table 2 Natural frequencies of frame structure alone with fixed boundaries condition.

\begin{tabular}{lll}
\hline No. of mode & Natural frequency $(f)\left(\mathrm{H}_{\mathrm{z}}\right)$ & Period $(\mathrm{sec})$ \\
\hline 1 & 0.042307 & 23.64 \\
2 & 0.042307 & 23.64 \\
3 & 0.055889 & 17.89 \\
4 & 0.14110 & 7.1 \\
5 & 0.14110 & 7.1 \\
6 & 0.14998 & 6.667 \\
7 & 0.17865 & 6 \\
\hline
\end{tabular}

Table 3 Natural frequencies of frame structure support by pile with spring.

\begin{tabular}{|c|c|c|c|c|}
\hline \multirow{3}{*}{ No. of mode } & \multicolumn{4}{|c|}{ Frame with pile foundation and linear spring — soft clay } \\
\hline & \multicolumn{2}{|c|}{ Case-1 } & \multicolumn{2}{|c|}{ Case-2 } \\
\hline & $\begin{array}{l}\text { Frequency } \\
(\mathrm{Hz})\end{array}$ & $\begin{array}{l}\text { Period } \\
(\mathrm{sec})\end{array}$ & $\begin{array}{l}\text { Frequency } \\
(\mathrm{Hz})\end{array}$ & $\begin{array}{l}\text { Period } \\
(\mathrm{sec})\end{array}$ \\
\hline 1 & 0.0071846 & 139.2 & 0.0071846 & 139.2 \\
\hline 2 & 0.023248 & 43 & 0.022892 & 43.68 \\
\hline 3 & 0.024697 & 40.49 & 0.024215 & 41.3 \\
\hline 4 & 0.052582 & 19 & 0.052582 & 19 \\
\hline 5 & 0.057123 & 17.5 & 0.057105 & 17.5 \\
\hline 6 & 0.057595 & 17.36 & 0.057595 & 17.36 \\
\hline 7 & 0.058388 & 17.13 & 0.058388 & 17.13 \\
\hline
\end{tabular}

Table 4 Natural frequencies of frame structure support by pile with spring.

\begin{tabular}{|c|c|c|c|c|}
\hline \multirow{3}{*}{ No. of mode } & \multicolumn{4}{|c|}{ Frame with pile foundation and linear spring — soft clay } \\
\hline & \multicolumn{2}{|c|}{ Case-3 } & \multicolumn{2}{|c|}{ Case-4 } \\
\hline & $\begin{array}{l}\text { Frequency } \\
(\mathrm{Hz})\end{array}$ & $\begin{array}{l}\text { Period } \\
(\mathrm{sec})\end{array}$ & $\begin{array}{l}\text { Frequency } \\
(\mathrm{Hz})\end{array}$ & $\begin{array}{l}\text { Period } \\
(\mathrm{sec})\end{array}$ \\
\hline 1 & 0.0071846 & 139.2 & 0.0071846 & 139.2 \\
\hline 2 & 0.023777 & 42.08 & 0.023633 & 42.3 \\
\hline 3 & 0.025405 & 39.36 & 0.025214 & 39.66 \\
\hline 4 & 0.052582 & 19 & 0.052582 & 19 \\
\hline 5 & 0.057149 & 17.5 & 0.057142 & 17.5 \\
\hline 6 & 0.057595 & 17.36 & 0.057595 & 17.36 \\
\hline 7 & 0.058388 & 17.13 & 0.058388 & 17.13 \\
\hline
\end{tabular}

Table 5 Natural frequencies of frame structure support by pile with spring.

\begin{tabular}{|c|c|c|c|c|}
\hline \multirow{3}{*}{ No. of mode } & \multicolumn{4}{|c|}{ Frame with pile foundation and linear spring — soft clay } \\
\hline & \multicolumn{2}{|c|}{ Case-5 } & \multicolumn{2}{|c|}{ Case-6 } \\
\hline & $\begin{array}{l}\text { Frequency } \\
(\mathrm{Hz})\end{array}$ & $\begin{array}{l}\begin{array}{l}\text { Period } \\
(\mathrm{sec})\end{array} \\
\end{array}$ & $\begin{array}{l}\text { Frequency } \\
(\mathrm{Hz})\end{array}$ & $\begin{array}{l}\begin{array}{l}\text { Period } \\
(\mathrm{sec})\end{array} \\
\end{array}$ \\
\hline 1 & 0.0071846 & 139.2 & 0.0071846 & 139.2 \\
\hline 2 & 0.023488 & 42.575 & 0.022706 & 44 \\
\hline 3 & 0.025020 & 39.97 & 0.023960 & 41.736 \\
\hline 4 & 0.052582 & 19 & 0.052582 & 19 \\
\hline 5 & 0.057135 & 17.5 & 0.057097 & 17.5 \\
\hline 6 & 0.057595 & 17.36 & 0.057595 & 17.36 \\
\hline 7 & 0.058388 & 17.13 & 0.058388 & 17.13 \\
\hline
\end{tabular}


Table 6 Natural frequencies of frame structure support by pile with spring.

\begin{tabular}{|c|c|c|c|c|}
\hline \multirow{3}{*}{ No. of mode } & \multicolumn{4}{|c|}{ Frame with pile foundation and linear spring - medium clay } \\
\hline & \multicolumn{2}{|c|}{ Case-1 } & \multicolumn{2}{|c|}{ Case-2 } \\
\hline & $\begin{array}{l}\text { Frequency } \\
(\mathrm{Hz})\end{array}$ & $\begin{array}{l}\text { Period } \\
(\mathrm{sec})\end{array}$ & $\begin{array}{l}\text { Frequency } \\
(\mathrm{Hz})\end{array}$ & $\begin{array}{l}\text { Period } \\
(\mathrm{sec})\end{array}$ \\
\hline 1 & 0.0071846 & 139.2 & 0.0071846 & 139.2 \\
\hline 2 & 0.024135 & 41.43 & 0.0238 & 42 \\
\hline 3 & 0.025878 & 38.64 & 0.025436 & 39.3 \\
\hline 4 & 0.052582 & 19 & 0.052582 & 19 \\
\hline 5 & 0.057167 & 17.5 & 0.05715 & 17.5 \\
\hline 6 & 0.057595 & 17.36 & 0.057595 & 17.36 \\
\hline 7 & 0.058388 & 17.13 & 0.058388 & 17.13 \\
\hline
\end{tabular}

Table 7 Natural frequencies of frame structure support by pile with spring.

\begin{tabular}{|c|c|c|c|c|}
\hline \multirow{3}{*}{ No. of mode } & \multicolumn{4}{|c|}{ Frame with pile foundation and linear spring — medium clay } \\
\hline & \multicolumn{2}{|c|}{ Case-3 } & \multicolumn{2}{|c|}{ Case-4 } \\
\hline & $\begin{array}{l}\text { Frequency } \\
(\mathrm{Hz})\end{array}$ & $\begin{array}{l}\text { Period } \\
(\mathrm{sec})\end{array}$ & $\begin{array}{l}\text { Frequency } \\
(\mathrm{Hz})\end{array}$ & $\begin{array}{l}\text { Period } \\
(\mathrm{sec})\end{array}$ \\
\hline 1 & 0.0071846 & 139.2 & 0.0071846 & 139.2 \\
\hline 2 & 0.024597 & 40.655 & 0.024468 & 40.87 \\
\hline 3 & 0.026481 & 37.76 & 0.026314 & 38 \\
\hline 4 & 0.052582 & 19 & 0.052582 & 19 \\
\hline 5 & 0.057191 & 17.5 & 0.057184 & 17.5 \\
\hline 6 & 0.057595 & 17.36 & 0.057595 & 17.36 \\
\hline 7 & 0.058388 & 17.13 & 0.058388 & 17.13 \\
\hline
\end{tabular}

Table 8 Natural frequencies of frame structure support by pile with spring.

\begin{tabular}{llclc}
\hline \multirow{2}{*}{ No. of mode } & \multicolumn{4}{c}{ Frame with pile foundation and linear spring- medium clay } \\
\cline { 2 - 5 } & \multicolumn{4}{c}{ Case-5 } \\
\cline { 2 - 5 } & $\begin{array}{l}\text { Frequency } \\
(\mathrm{Hz})\end{array}$ & $\begin{array}{l}\text { Period } \\
(\mathrm{sec})\end{array}$ & $\begin{array}{l}\text { Frequency } \\
(\mathrm{Hz})\end{array}$ & $\begin{array}{l}\text { Period } \\
(\mathrm{sec})\end{array}$ \\
\hline 1 & 0.0071846 & 139.2 & 0.0071846 & 139.2 \\
2 & 0.024341 & 41 & 0.023615 & 42.35 \\
3 & 0.026148 & 38.24 & 0.025189 & 39.7 \\
4 & 0.052582 & 19 & 0.052582 & 19 \\
5 & 0.057178 & 17.5 & 0.057141 & 17.5 \\
6 & 0.057595 & 17.36 & 0.057595 & 17.36 \\
7 & 0.058388 & 17.13 & 0.058388 & 17.13 \\
\hline
\end{tabular}

Table 9 Natural frequencies of frame structure support by pile with spring.

\begin{tabular}{|c|c|c|c|c|}
\hline \multirow{3}{*}{ No. of mode } & \multicolumn{4}{|c|}{ Frame with pile foundation and linear spring — dense sand } \\
\hline & \multicolumn{2}{|c|}{ Case-1 } & \multicolumn{2}{|c|}{ Case-2 } \\
\hline & $\begin{array}{l}\text { Frequency } \\
(\mathrm{Hz})\end{array}$ & $\begin{array}{l}\text { Period } \\
(\mathrm{sec})\end{array}$ & $\begin{array}{l}\text { Frequency } \\
(\mathrm{Hz})\end{array}$ & $\begin{array}{l}\text { Period } \\
(\mathrm{sec})\end{array}$ \\
\hline 1 & 0.0071846 & 139.2 & 0.0071846 & 139.2 \\
\hline 2 & 0.024731 & 40.435 & 0.024628 & 40.6 \\
\hline 3 & 0.026655 & 37.5 & 0.026521 & 37.71 \\
\hline 4 & 0.052582 & 19 & 0.052582 & 19 \\
\hline 5 & 0.057198 & 17.5 & 0.057192 & 17.5 \\
\hline 6 & 0.057595 & 17.36 & 0.057595 & 17.13 \\
\hline 7 & 0.058388 & 17.13 & 0.058388 & 17.13 \\
\hline
\end{tabular}


Table 10 Natural frequencies of frame structure support by pile with spring.

\begin{tabular}{|c|c|c|c|c|}
\hline \multirow{3}{*}{ No. of mode } & \multicolumn{4}{|c|}{ Frame with pile foundation and linear spring — dense sand } \\
\hline & \multicolumn{2}{|c|}{ Case-3 } & \multicolumn{2}{|c|}{ Case-4 } \\
\hline & $\begin{array}{l}\text { Frequency } \\
(\mathrm{Hz})\end{array}$ & $\begin{array}{l}\text { Period } \\
(\mathrm{sec})\end{array}$ & $\begin{array}{l}\text { Frequency } \\
(\mathrm{Hz})\end{array}$ & $\begin{array}{l}\text { Period } \\
(\mathrm{sec})\end{array}$ \\
\hline 1 & 0.0071846 & 139.2 & 0.0071846 & 139.2 \\
\hline 2 & 0.025669 & 38.98 & 0.025078 & 39.876 \\
\hline 3 & 0.027848 & 35.91 & 0.0271 & 36.9 \\
\hline 4 & 0.052582 & 19 & 0.052582 & 19 \\
\hline 5 & 0.057248 & 17.5 & 0.057216 & 17.5 \\
\hline 6 & 0.057595 & 17.36 & 0.057595 & 17.36 \\
\hline 7 & 0.058388 & 17.13 & 0.058388 & 17.13 \\
\hline
\end{tabular}

Table 11 Natural frequencies of frame structure support by pile with spring.

\begin{tabular}{llc}
\hline & \multicolumn{2}{c}{ Frame with pile foundation and linear spring-dense sand } \\
\cline { 2 - 3 } No. of mode & $\begin{array}{l}\text { Frequency } \\
(\mathrm{Hz})\end{array}$ & $\begin{array}{l}\text { Period } \\
(\mathrm{sec})\end{array}$ \\
\hline 1 & 0.0071846 & 139.2 \\
2 & 0.024256 & 41.23 \\
3 & 0.026036 & 38.41 \\
4 & 0.052582 & 19 \\
5 & 0.057173 & 17.5 \\
6 & 0.057595 & 17.36 \\
7 & 0.058388 & 17.13 \\
\hline
\end{tabular}

Table 12 Variation of the natural frequencies of frame structure and pile foundation with different soil type (perfect bond case-half space 1).

\begin{tabular}{llcllll}
\hline \multirow{2}{*}{ No. of mode } & \multicolumn{3}{c}{ Soft clay } & \multicolumn{2}{c}{ Medium clay } & \multicolumn{2}{c}{ Dense Sand } \\
\cline { 2 - 7 } & $\begin{array}{l}\text { Frequency } \\
(\mathrm{Hz})\end{array}$ & $\begin{array}{l}\text { Period } \\
(\mathrm{sec})\end{array}$ & $\begin{array}{l}\text { Frequency } \\
(\mathrm{Hz})\end{array}$ & $\begin{array}{l}\text { Period } \\
(\mathrm{sec})\end{array}$ & $\begin{array}{l}\text { Frequency } \\
(\mathrm{Hz})\end{array}$ & $\begin{array}{l}\text { Period } \\
(\mathrm{sec})\end{array}$ \\
\hline 1 & 0.028772 & 34.756 & 0.031007 & 32.25 & 0.032639 & 30.638 \\
2 & 0.032753 & 30.53 & 0.034732 & 28.79 & 0.036076 & 27.72 \\
3 & 0.040911 & 24.44 & 0.043576 & 22.948 & 0.045452 & 22 \\
4 & 0.076374 & 13.1 & 0.098473 & 10.155 & 0.11008 & 9.1 \\
5 & 0.076841 & 13 & 0.098475 & 10.155 & 0.11405 & 8.768 \\
6 & 0.077926 & 12.83 & 0.098972 & 10.1 & 0.11534 & 8.67 \\
7 & 0.082691 & 12.09 & 0.10690 & 9.35 & 0.12311 & 8.123 \\
\hline
\end{tabular}

Table 13 Variation of the natural frequencies of frame structure and pile foundation with different soil type (perfect bond case-half space 2 ).

\begin{tabular}{lllllll}
\hline \multirow{2}{*}{ No. of mode } & \multicolumn{3}{c}{ Soft clay } & \multicolumn{2}{c}{ Medium clay } & \multicolumn{2}{c}{ Dense Sand } \\
\cline { 2 - 7 } & $\begin{array}{l}\text { Frequency } \\
(\mathrm{Hz})\end{array}$ & $\begin{array}{l}\text { Period } \\
(\mathrm{sec})\end{array}$ & $\begin{array}{l}\text { Frequency } \\
(\mathrm{Hz})\end{array}$ & $\begin{array}{l}\text { Period } \\
(\mathrm{sec})\end{array}$ & $\begin{array}{l}\text { Frequency } \\
(\mathrm{Hz})\end{array}$ & $\begin{array}{l}\text { Period } \\
(\mathrm{sec})\end{array}$ \\
\hline 1 & 0.027624 & 36.2 & 0.030460 & 32.83 & 0.032385 & 30.9 \\
2 & 0.031060 & 32.2 & 0.033968 & 29.44 & 0.035738 & 27.98 \\
3 & 0.037813 & 26.445 & 0.041007 & 24.39 & 0.043194 & 23.15 \\
4 & 0.045755 & 21.855 & 0.05999 & 16.669 & 0.069279 & 14.43 \\
5 & 0.045834 & 21.82 & 0.060049 & 16.653 & 0.075173 & 13.3 \\
6 & 0.045839 & 21.82 & 0.060052 & 16.652 & 0.075202 & 13.29 \\
7 & 0.050784 & 19.69 & 0.066298 & 15.08 & 0.084215 & 11.87 \\
\hline
\end{tabular}




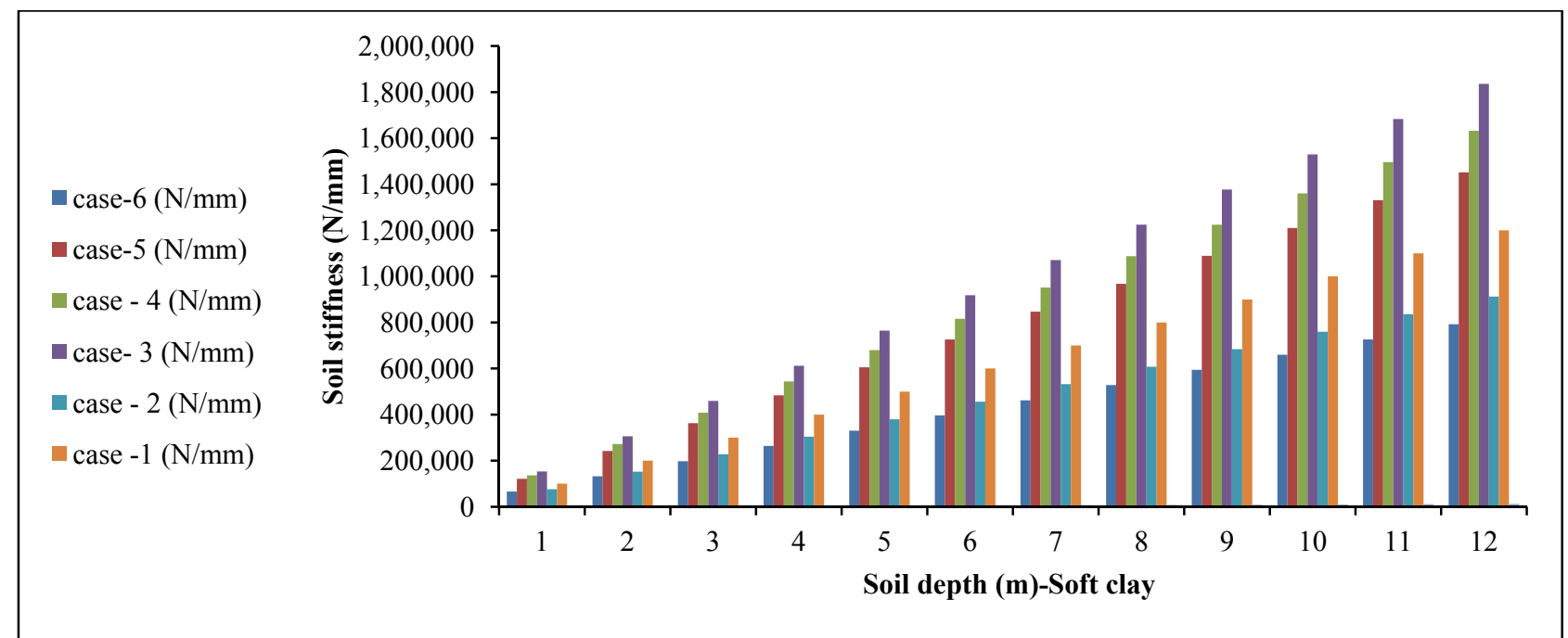

Fig. 1 Variation of stiffness with depth.

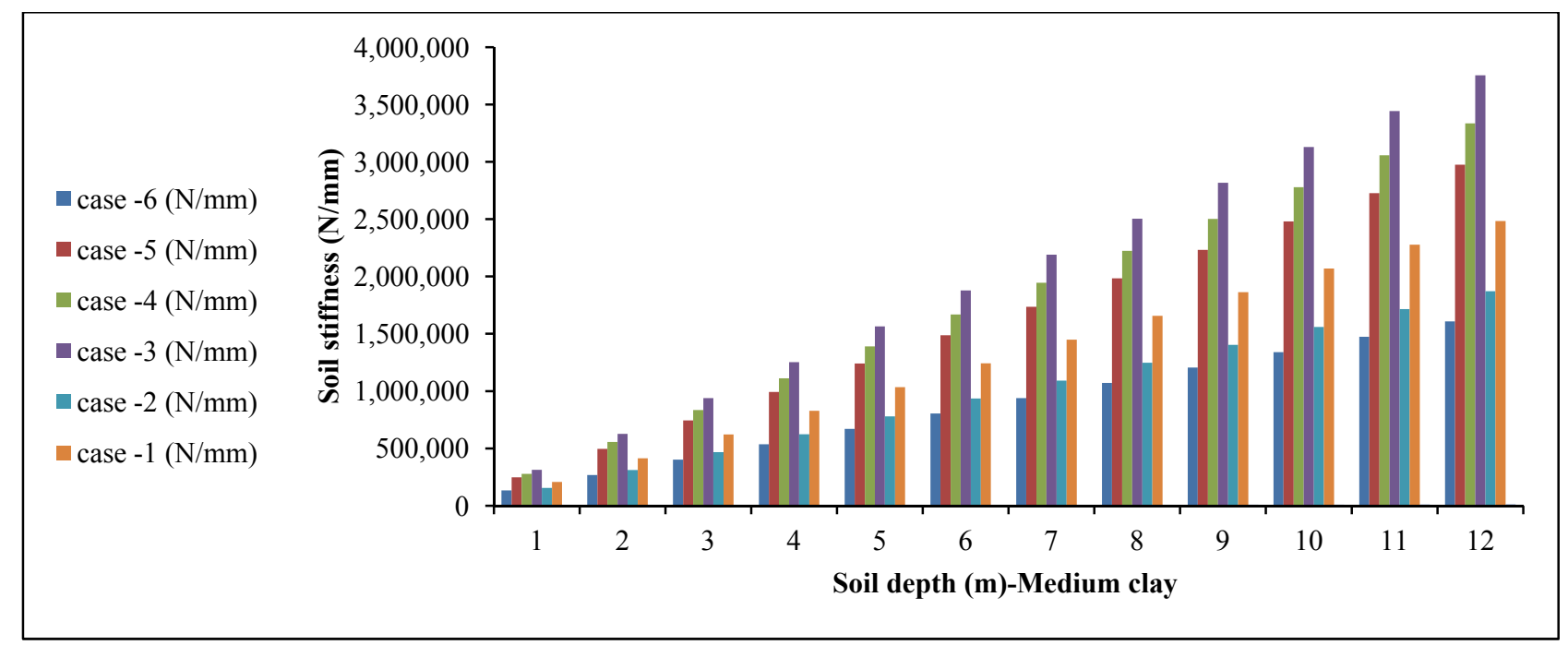

Fig. 2 Variation of stiffness with depth.

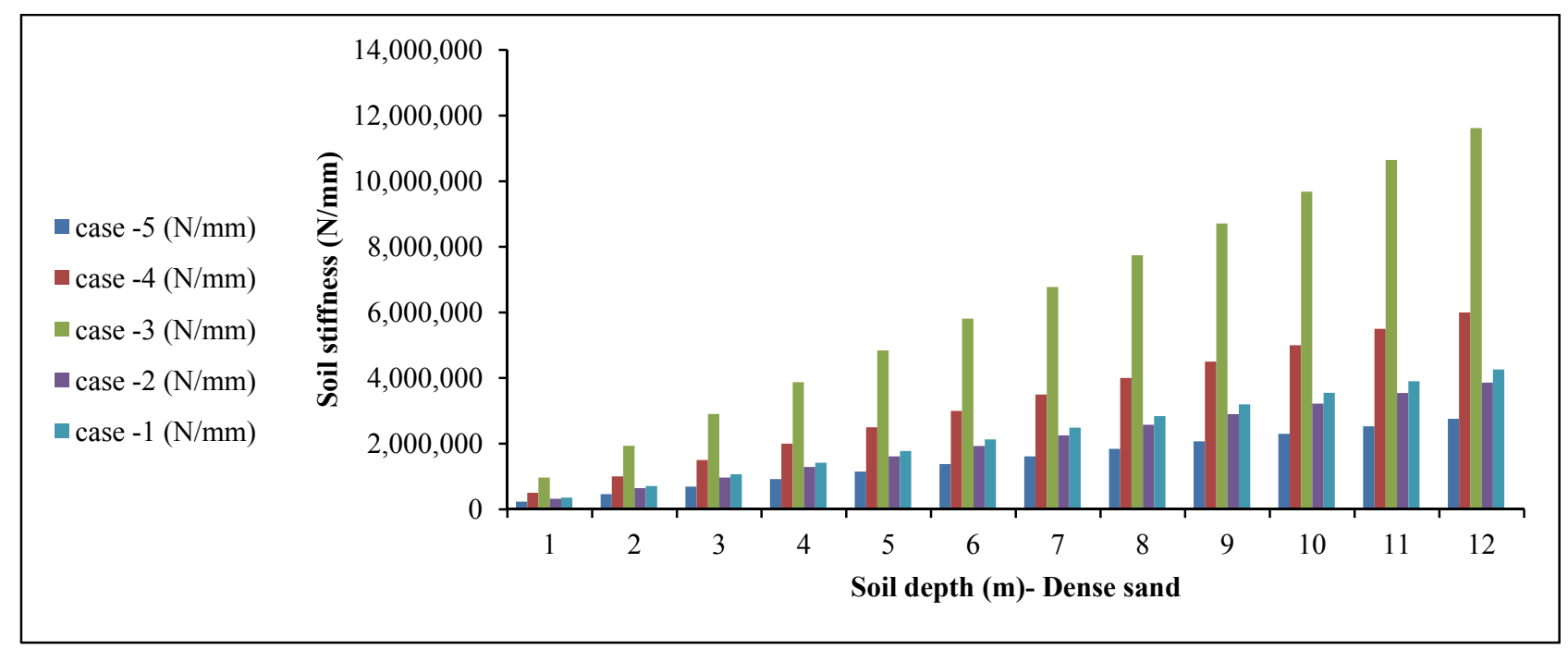

Fig. 3 Variation of stiffness with depth. 
surrounding soil (half space-1), the period range equal to $1.47,1.364$ and 1.296 when the piles embedded into soft clay, medium clay and dense gravel respectively. Also in the case of perfect bond between piles and surrounding soil (half space-2), the period range equal to $1.53,1.39$ and 1.31 when the piles embedded into soft clay, medium clay and dense gravel respectively. This comparative are based on the first natural period only. The clarification for changing in period from case to case occurs due to change in size of half space, soil type and soil modulus of elasticity. These variations in the periods from the first mode to seven (last) mode for the same frame indicates the higher difference in the stiffness between the three cases and that will be reflected in the forced vibration analysis of the frame structure. Comparing the results of natural frequencies in Table 2 with Tables 12 and 13, clarifies that the natural frequencies values of the frame alone is higher than their respective values in soil half spaces. The reasons of the difference are due to the inclusion of the inertia (mass) of the soil in the model which lead to a reduction in the stiffness and as more mass adds as more stiffness reduced [6]. Also, it is clear that increasing the stiffness of the soil increases the natural frequencies of the building. In the case of non-fixed boundary conditions of the building, the stiffness of the building and then the natural frequencies are inversely proportional to the relative stiffness at the boundary conditions [6]. Research has shown that soil-structure interaction increase the time period in structural models [14]. Also $(\mathrm{T}=1 / f)$ from this relation, it is shown that the period has inversely proportional with natural frequency which mean the increase of period lead to decrease in natural frequency or inversely [15]. In this study, it is obtained increase in time period when the authors consider soil-structures interaction as compare with frame alone as shown in Tables 2-13.

\subsection{Forced Vibration Analysis}

In this part, the dynamic response of the frame structure with piles foundation is investigated due to applied lateral harmonic load. Also, the soil-structure interactions are investigated. Properties of the soil types are same as in the analysis of free vibration in Table 1. A concentrated harmonic load is applied on the joint of frame structure which has the following characteristics:

$$
\mathrm{F}(\mathrm{t})=\mathrm{P} \cos \omega \mathrm{t}(\mathrm{KN})
$$

Where, $\mathrm{P}$ is the amplitude of the forces $(\mathrm{KN})$; $\dot{\omega}$ is the excitation frequency $(\mathrm{rad} / \mathrm{sec})$. The effects of the following parameters on the response are considered:

- Effect of base boundary conditions on the resulted displacements of the frame;

- Type of soil (soil properties);

- Effect of flexibility;

- Variation in the excitation frequency.

The horizontal displacement of a last storey of frame structure in the $\mathrm{x}$-direction is considered as a response of the frame to the exciting load. Figs. 4-6 show the displacement at the last storey of frame structure. The particular selection of the horizontal displacement at last storey of frame is due to:

(1) The lowest natural frequencies are in the horizontal mode;

(2) A comparison is made among the horizontal displacement in all stories of frame structure started from foundation level to last storey. It is clear from the comparison results that the magnitudes of the displacements at last storey are higher as shown in Figs. 4-6. Where the frequency of the load considered is equal to the first natural frequency of frame structure with fixed boundaries.

Due to the above point, the multi storey frame structure can be considered as cantilever. When excited, it will vibrate mainly in its lowest modes (horizontal or sway mode) producing larger vibrations at the last storey or free end of frame.

4.2.1 Effect of Base Boundary Conditions on the Resulted Displacements of the Frame

In this case, the frame structure model is analyzed to consider the effect of base fixation on the results of 
Fixed base

soft clay-case1

softclay-case 2

soft clay-case 3

soft clay-case4

soft clay-case 5

soft clay-case6

soft clay-halfspace1

soft clay-halfspace2

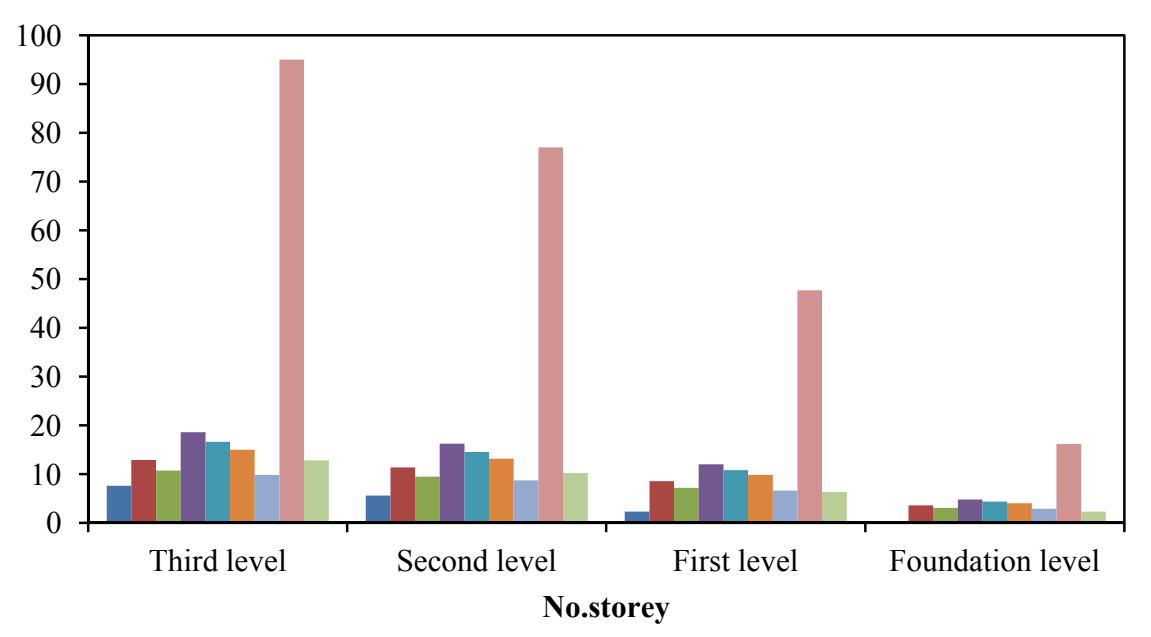

Fig. 4 Variation of displacement with storey.

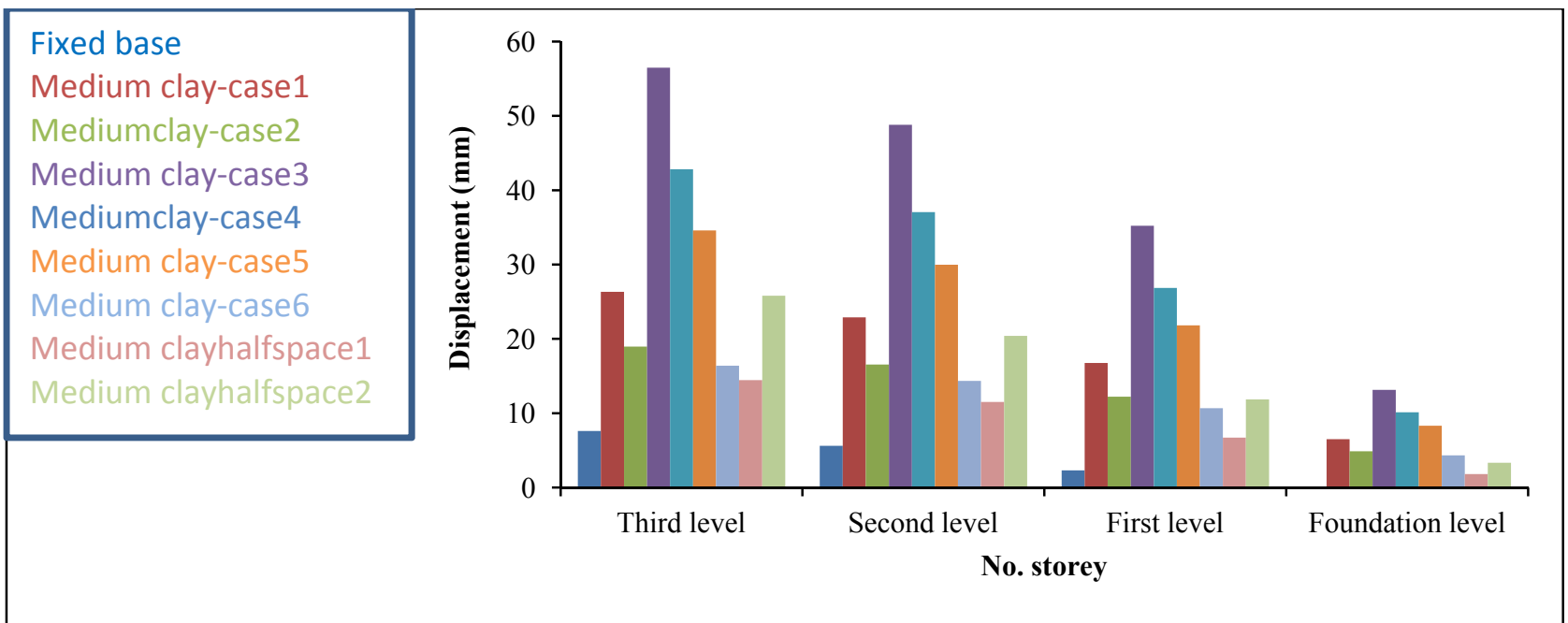

Fig. 5 Variation of displacement with storey.

Fixed base

Dense gravel-case 1

Dense gravel-case2

Dense gravel-case 3

Dense gravel-case4

Dense gravel-case 5

Dense gravel-halfspace 1

Dense gravel-halfspace2

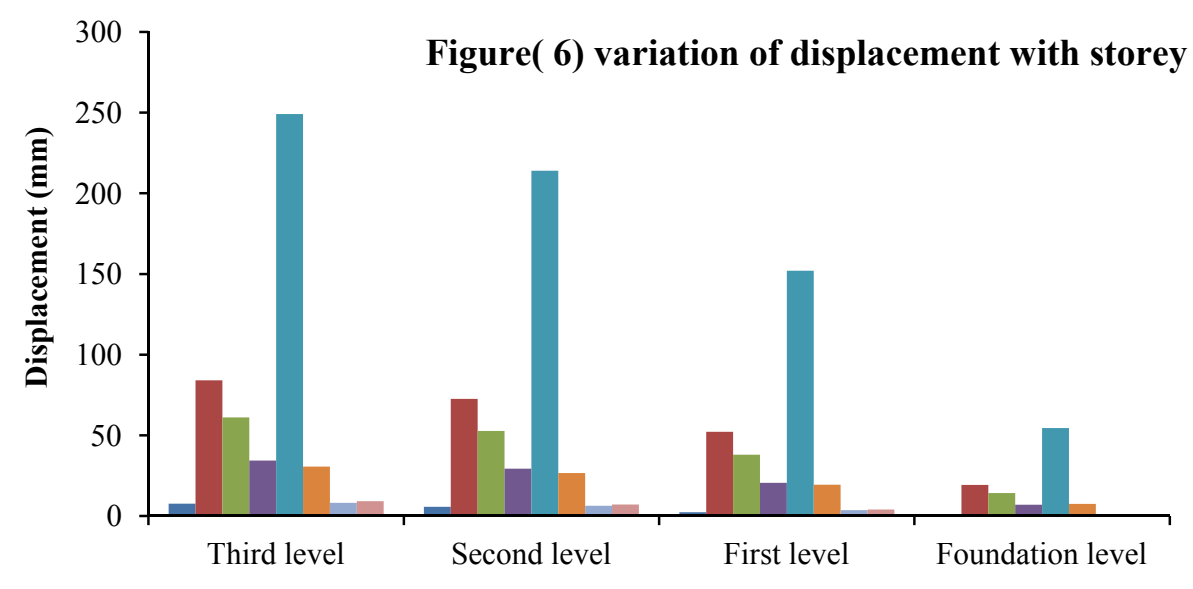

No. storey

Fig. 6 Variation of displacement with store. 
the frame displacements due to lateral harmonic loads. Tables 14-36 show the effects of base boundary conditions on the resulted displacement. They include the comparisons between the frame with piles and linear spring. Frame with piles have perfect bond with surrounding soil of frame with fixed boundary condition. Also, this comparison includes different cases such as the properties of linear spring and size of half space. Fixed base boundary condition is more stiff than other boundary conditions. Therefore, the response of the frame structure in case of fixed base is less than other condition of frame with foundation [16]. Also, it is known that increasing the flexibility of the structure foundation will increase the structure flexibility [4]. So, the effect of soil structure interaction increases the displacement as compare with fixed base.

\subsubsection{Effect of Soil Type}

Three types of soils that are differed in properties are considered in this case study. These soils are soft silty clay soil, medium silty clay and dense sandy gravel. Soil properties are given in Table 1. It is clear in Figs. 7-9 that the response of frame structure change from case to case when soil type change. When the soil is modeled as the discrete independent linear springs, it appears that the frame have higher

Table 14 Values of displacements (mm) and corresponding increase due to soil-structure interaction (SSI) - (pile base with winkler spring-piles embedded into soft clay-case-1).

\begin{tabular}{llll}
\hline Storey height $(\mathrm{m})$ & Fixed base & SSI & \% Variation \\
\hline 10.5 & 7.6 & 12.923 & 1.7 \\
7 & 5.6 & 11.363 & 2.02 \\
3 & 2.3 & 8.535 & 3.711 \\
0 & 0 & 3.57 & 3.57 \\
\hline
\end{tabular}

Table 15 Values of displacements (mm) and corresponding increase due to soil-structure interaction (SSI) - (pile base with winkler spring-piles embedded into soft clay-case-2).

\begin{tabular}{llll}
\hline Storey height $(\mathrm{m})$ & Fixed base & SSI & \% Variation \\
\hline 10.5 & 7.6 & 10.715 & 1.41 \\
7 & 5.6 & 9.47 & 1.691 \\
3 & 2.3 & 7.183 & 3.123 \\
0 & 0 & 3.094 & 3.094 \\
\hline
\end{tabular}

Table 16 Values of displacements $(\mathrm{mm})$ and corresponding increase due to soil-structure interaction (SSI) - (pile base with winkler spring-piles embedded into soft clay-case-3).

\begin{tabular}{llll}
\hline Storey height $(\mathrm{m})$ & Fixed base & SSI & \% Variation \\
\hline 10.5 & 7.6 & 18.58 & 2.444 \\
7 & 5.6 & 16.226 & 2.9 \\
3 & 2.3 & 12 & 5.218 \\
0 & 0 & 4.8 & 4.8 \\
\hline
\end{tabular}

Table 17 Values of displacements ( $\mathrm{mm}$ ) and corresponding increase due to soil-structure interaction (SSI) - (pile base with winkler spring-piles embedded into soft clay-case-4).

\begin{tabular}{llll}
\hline Storey height $(\mathrm{m})$ & Fixed base & SSI & \% Variation \\
\hline 10.5 & 7.6 & 16.611 & 2.186 \\
7 & 5.6 & 14.533 & 2.595 \\
3 & 2.3 & 10.794 & 4.7 \\
0 & 0 & 4.373 & 4.373 \\
\hline
\end{tabular}


Table 18 Values of displacements $(\mathrm{mm})$ and corresponding increase due to soil-structure interaction (SSI) - (pile base with winkler spring-piles embedded into soft clay-case-5).

\begin{tabular}{llll}
\hline Storey height $(\mathrm{m})$ & Fixed base & SSI & \% Variation \\
\hline 10.5 & 7.6 & 15 & 1.974 \\
7 & 5.6 & 13.153 & 2.349 \\
3 & 2.3 & 9.81 & 4.265 \\
0 & 0 & 4.02 & 4.02 \\
\hline
\end{tabular}

Table 19 Values of displacements ( $\mathrm{mm}$ ) and corresponding increase due to soil-structure interaction (SSI)—(pile base with winkler spring-piles embedded into soft clay-case-6).

\begin{tabular}{llll}
\hline Storey height $(\mathrm{m})$ & Fixed base & SSI & \% Variation \\
\hline 10.5 & 7.6 & 9.83 & 1.293 \\
7 & 5.6 & 8.705 & 1.55 \\
3 & 2.3 & 6.64 & 2.9 \\
0 & 0 & 2.9 & 2.9 \\
\hline
\end{tabular}

Table 20 Values of displacements ( $\mathrm{mm}$ ) and corresponding increase due to soil-structure interaction (SSI) - (pile base with winkler spring-piles embedded into medium clay-case-1).

\begin{tabular}{llll}
\hline Storey height $(\mathrm{m})$ & Fixed base & SSI & \% Variation \\
\hline 10.5 & 7.6 & 26.323 & 3.464 \\
7 & 5.6 & 22.881 & 4.1 \\
3 & 2.3 & 16.745 & 7.28 \\
0 & 0 & 6.5 & 6.5 \\
\hline
\end{tabular}

Table 21 Values of displacements ( $\mathrm{mm}$ ) and corresponding increase due to soil-structure interaction (SSI) - (pile base with winkler spring-piles embedded into medium clay-case-2).

\begin{tabular}{llll}
\hline Storey height $(\mathrm{m})$ & Fixed base & SSI & \% Variation \\
\hline 10.5 & 7.6 & 18.95 & 2.5 \\
7 & 5.6 & 16.54 & 2.953 \\
3 & 2.3 & 12.22 & 5.313 \\
0 & 0 & 4.88 & 4.88 \\
\hline
\end{tabular}

Table 22 Values of displacements $(\mathrm{mm})$ and corresponding increase due to soil-structure interaction (SSI) - (pile base with winkler spring-piles embedded into medium clay-case-3).

\begin{tabular}{llll}
\hline Storey height $(\mathrm{m})$ & Fixed base & SSI & \% Variation \\
\hline 10.5 & 7.6 & 56.48 & 7.43 \\
7 & 5.6 & 48.801 & 8.7144 \\
3 & 2.3 & 35.227 & 15.316 \\
0 & 0 & 13.14 & 13.14 \\
\hline
\end{tabular}

Table 23 Values of displacements $(\mathrm{mm})$ and corresponding increase due to soil-structure interaction (SSI) - (pile base with winkler spring-piles embedded into medium clay-case-4).

\begin{tabular}{lllc}
\hline Storey height $(\mathrm{m})$ & Fixed base & SSI & \% Variation \\
\hline 10.5 & 7.6 & 42.83 & 5.636 \\
7 & 5.6 & 37.06 & 6.618 \\
3 & 2.3 & 26.86 & 11.7 \\
0 & 0 & 10.134 & 10.134 \\
\hline
\end{tabular}


Table 24 Values of displacements $(\mathrm{mm})$ and corresponding increase due to soil-structure interaction (SSI) - (pile base with winkler spring-piles embedded into medium clay-case-5).

\begin{tabular}{llll}
\hline Storey height $(\mathrm{m})$ & Fixed base & SSI & \% Variation \\
\hline 10.5 & 7.6 & 34.58 & 4.55 \\
7 & 5.6 & 29.98 & 5.354 \\
3 & 2.3 & 21.805 & 9.5 \\
0 & 0 & 8.317 & 8.317 \\
\hline
\end{tabular}

Table 25 Values of displacements ( $\mathrm{mm}$ ) and corresponding increase due to soil-structure interaction (SSI)—(pile base with winkler spring-piles embedded into medium clay-case-6).

\begin{tabular}{llll}
\hline Storey height $(\mathrm{m})$ & Fixed base & SSI & \% Variation \\
\hline 10.5 & 7.6 & 16.39 & 2.16 \\
7 & 5.6 & 14.34 & 2.56 \\
3 & 2.3 & 10.66 & 4.64 \\
0 & 0 & 4.325 & 4.325 \\
\hline
\end{tabular}

Table 26 Values of displacements ( $\mathrm{mm}$ ) and corresponding increase due to soil-structure interaction (SSI) - (pile base with winkler spring-piles embedded into dense sand-case-1).

\begin{tabular}{llll}
\hline Storey height $(\mathrm{m})$ & Fixed base & SSI & \% Variation \\
\hline 10.5 & 7.6 & 84.1 & 11.07 \\
7 & 5.6 & 72.53 & 12.952 \\
3 & 2.3 & 52.15 & 22.7 \\
0 & 0 & 19.225 & 19.225 \\
\hline
\end{tabular}

Table 27 Values of displacements ( $\mathrm{mm}$ ) and corresponding increase due to soil-structure interaction (SSI) - (pile base with winkler spring-piles embedded into dense sand-case-2).

\begin{tabular}{lllc}
\hline Storey height $(\mathrm{m})$ & Fixed base & SSI & \% Variation \\
\hline 10.5 & 7.6 & 61.1 & 8.04 \\
7 & 5.6 & 52.73 & 9.416 \\
3 & 2.3 & 38 & 16.52 \\
0 & 0 & 14.15 & 14.15 \\
\hline
\end{tabular}

Table 28 Values of displacements $(\mathrm{mm})$ and corresponding increase due to soil-structure interaction (SSI) - (pile base with winkler spring-piles embedded into dense sand-case-3).

\begin{tabular}{llll}
\hline Storey height $(\mathrm{m})$ & Fixed base & SSI & \% Variation \\
\hline 10.5 & 7.6 & 34.36 & 4.521 \\
7 & 5.6 & 29.3 & 5.232 \\
3 & 2.3 & 20.47 & 8.9 \\
0 & 0 & 7 & 7 \\
\hline
\end{tabular}

Table 29 Values of displacements $(\mathrm{mm})$ and corresponding increase due to soil-structure interaction (SSI) - (pile base with winkler spring-piles embedded into dense sand-case-4).

\begin{tabular}{llll}
\hline Storey height $(\mathrm{m})$ & Fixed base & SSI & \% Variation \\
\hline 10.5 & 7.6 & 249.1 & 32.776 \\
7 & 5.6 & 214 & 38.214 \\
3 & 2.3 & 152 & 66.1 \\
0 & 0 & 54.41 & 54.41 \\
\hline
\end{tabular}


Table 30 Values of displacements $(\mathrm{mm})$ and corresponding increase due to soil-structure interaction (SSI) - (pile base with winkler spring-piles embedded into dense sand-case-5).

\begin{tabular}{llll}
\hline Storey height $(\mathrm{m})$ & Fixed base & SSI & \% Variation \\
\hline 10.5 & 7.6 & 30.62 & 4.03 \\
7 & 5.6 & 26.57 & 4.745 \\
3 & 2.3 & 19.375 & 8.424 \\
0 & 0 & 7.445 & 7.445 \\
\hline
\end{tabular}

Table 31 Values of displacements $(\mathrm{mm})$ and corresponding increase due to soil-structure interaction (SSI) - (perfect bond-soft clay-halfspace-1).

\begin{tabular}{llll}
\hline Storey height $(\mathrm{m})$ & Fixed base & SSI & \% Variation \\
\hline 10.5 & 7.6 & 95 & 12.5 \\
7 & 5.6 & 77 & 13.75 \\
3 & 2.3 & 47.71 & 20.75 \\
0 & 0 & 16.2 & 16.2 \\
\hline
\end{tabular}

Table 32 Values of displacements $(\mathrm{mm})$ and corresponding increase due to soil-structure interaction (SSI)—(perfect bond-medium clay-halfspace-1).

\begin{tabular}{llll}
\hline Storey height $(\mathrm{m})$ & Fixed base & SSI & \% Variation \\
\hline 10.5 & 7.6 & 14.45 & 1.9 \\
7 & 5.6 & 11.5 & 2 \\
3 & 2.3 & 6.7 & 2.91 \\
0 & 0 & 1.8 & 1.8 \\
\hline
\end{tabular}

Table 33 Values of displacements $(\mathrm{mm})$ and corresponding increase due to soil-structure interaction (SSI) - (perfect bond-dense gravel-halfspace-1).

\begin{tabular}{llll}
\hline Storey height $(\mathrm{m})$ & Fixed base & SSI & \% Variation \\
\hline 10.5 & 7.6 & 8.1 & 1.07 \\
7 & 5.6 & 6.34 & 1.132 \\
3 & 2.3 & 3.53 & 1.535 \\
0 & 0 & 0.8 & 0.8 \\
\hline
\end{tabular}

Table 34 Values of displacements $(\mathrm{mm})$ and corresponding increase due to soil-structure interaction (SSI) - (perfect bond-soft clay-halfspace-2).

\begin{tabular}{llll}
\hline Storey height $(\mathrm{m})$ & Fixed base & SSI & \% Variation \\
\hline 10.5 & 7.6 & 12.8 & 1.68 \\
7 & 5.6 & 10.2 & 1.82 \\
3 & 2.3 & 6.31 & 2.74 \\
0 & 0 & 2.3 & 2.3 \\
\hline
\end{tabular}

Table 35 Values of displacements $(\mathrm{mm})$ and corresponding increase due to soil-structure interaction (SSI) - (perfect bond-medium clay-halfspace-2).

\begin{tabular}{llll}
\hline Storey height $(\mathrm{m})$ & Fixed base & SSI & \% Variation \\
\hline 10.5 & 7.6 & 25.8 & 3.4 \\
7 & 5.6 & 20.4 & 3.64 \\
3 & 2.3 & 11.86 & 5.16 \\
0 & 0 & 3.32 & 3.32 \\
\hline
\end{tabular}


Table 36 Values of displacements $(\mathrm{mm})$ and corresponding increase due to soil-structure interaction (SSI) - (perfect bond-dense gravel-halfspace-2).

\begin{tabular}{llll}
\hline Storey height $(\mathrm{m})$ & Fixed base & SSI & \% Variation \\
\hline 10.5 & 7.6 & 9.1 & 1.2 \\
7 & 5.6 & 7.12 & 1.3 \\
3 & 2.3 & 4 & 1.74 \\
0 & 0 & 0.9 & 0.9 \\
\hline
\end{tabular}

displacement when the linear spring represent medium clay as compare with soft clay. For dense gravel, the obtained displacement is higher as comparing with clay when the dense gravel represented by linear spring. In the perfect bond case, the higher displacement of frame occurs when the piles embedded in soft clay as comparing with medium clay and dense gravel. The effect of the size of the half space is clearly shown the response increase by increasing the size of half space for all cases (halfspace-1 and halfspace-2) in perfect bond. This is due to the fact that increasing the size increase the masses included and thus, reduces the stiffness of the system. On the other hand, in spite of increasing the size of half space, the response of frame's decrease due to the interaction between the frequencies of applied load and frequencies of frame structure.

\subsubsection{Effect of Flexibility}

It can be seen in Figs. 7-9 that for all the cases studied, results obtained with piles and soil as series of linear elastic spring are higher than those obtained with fixed base. Also, results obtained with piles embedded in soil halfspace are higher than those obtained with fixed base. It is known that increasing the flexibility of the structure foundation will increase the structure flexibility. Generally, the obtained result in case of linear discrete independent spring which is used to represent the soil stiffness is greater than the perfect bond between piles and surrounding soil. It is due to the increasing in the magnitude of natural period in case of linear discrete spring will reflect on the response of piles as comparing with perfect bond. Except the response of frame in case of piles embedded in soft clay, halfspace-1 is higher than frame with piles and linear elastic spring. It is used to represent the stiffness of soft clay due to the interaction between the frequencies of applied load and frame structure.

\subsubsection{Variation in the Excitation Frequency}

It is commonly accepted that structures normally responded at their fundamental frequencies and low vibration modes as the energy required to deform the structures in their low modes is a minimum [6]. To test the effect of the frequency of the applied load, the load case is repeated 7 times with a different frequency in each time. The frequency range used is from 0.5-1.5 times the first natural frequency of frame structure with fixed boundary condition. The values of the excitation frequencies are as following:

Lower limit of frequency range of excitation $=0.5$ $f_{1}$ frame structure

$$
\begin{gathered}
=0.5 \times 0.042307 \\
=0.021 \mathrm{~Hz}
\end{gathered}
$$

Upper limit of frequency range of excitation $=1.5$ $f_{1}$ frame structure

$$
\begin{gathered}
=1.5 \times 0.042307 \\
=0.063 \mathrm{~Hz}
\end{gathered}
$$

The values of the seven cases of excitation frequencies in $\mathrm{Hz}$ are listed in Table 37.

$$
f_{i}=\frac{\omega_{i}}{2 \pi}
$$

Where,

$f_{i}=\operatorname{excitation}$ frequency $(\mathrm{Hz})$;

$\omega_{i}=$ excitation frequency (radian per second).

Each case of excitation frequency is applied as separate frequency. And the equation of motion solved for each case alone to determine the dynamic response of the frame structure for different base fixations that considered on this study. The effect of soil structure interaction lead to versus the frequency ratio (r) 


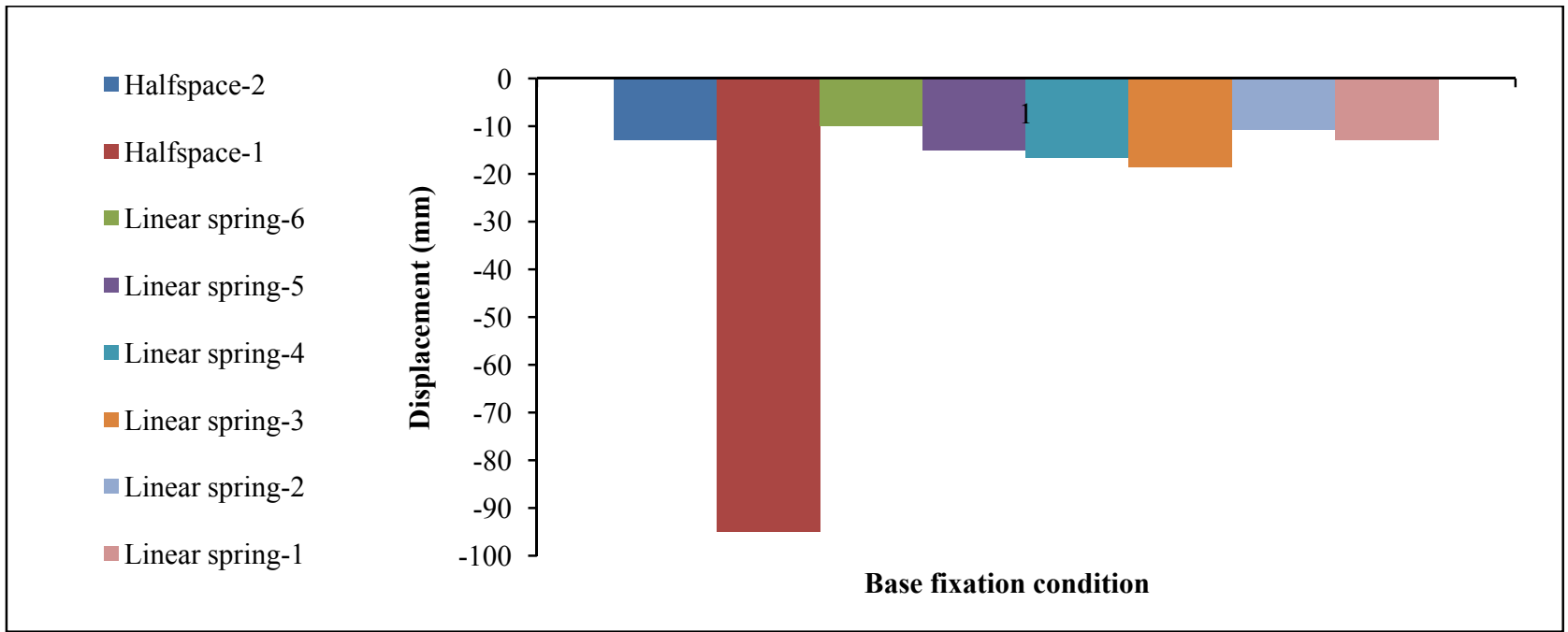

Fig. 7 Variation of frame displacement-soft clay type.

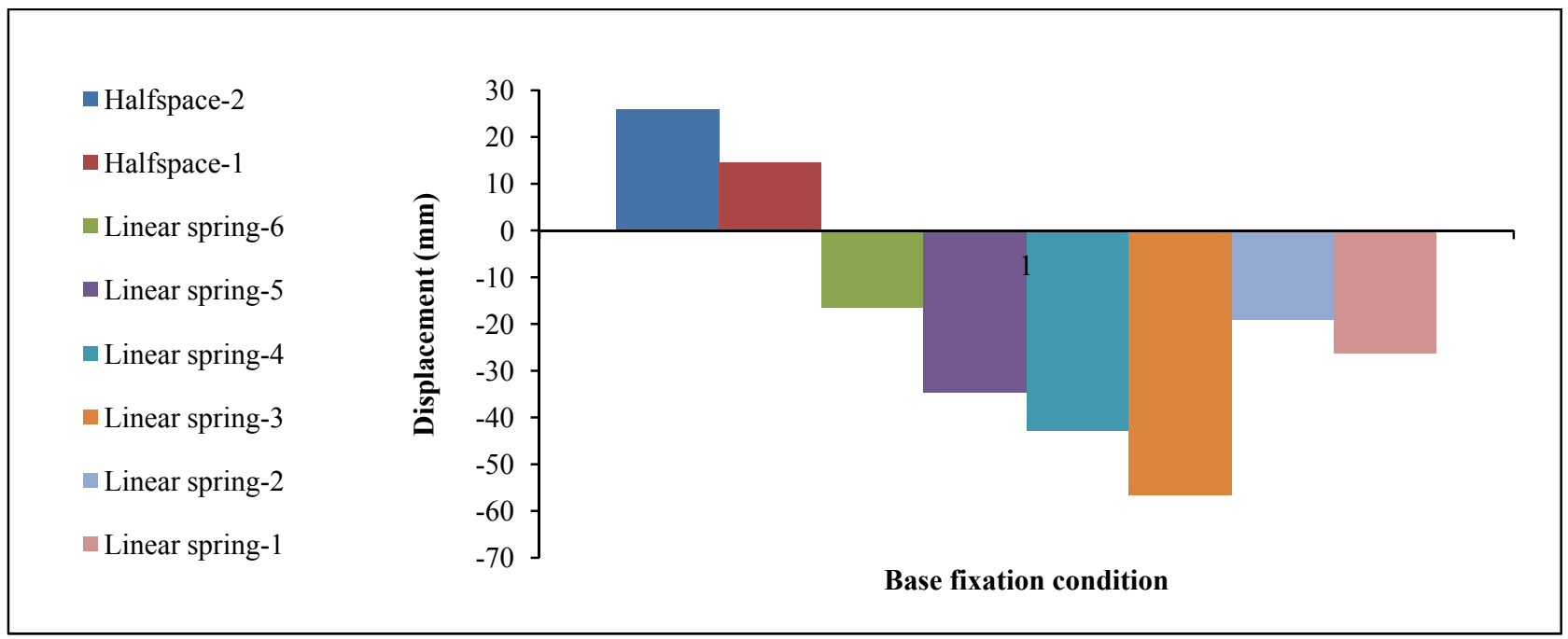

Fig. 8 Variation of frame displacement-medium clay type.

- Halfspace-2

- Halfspace-1

- Linear spring-5

- Linear spring-4

- Linear spring-3

- Linear spring-2

- Linear spring-1

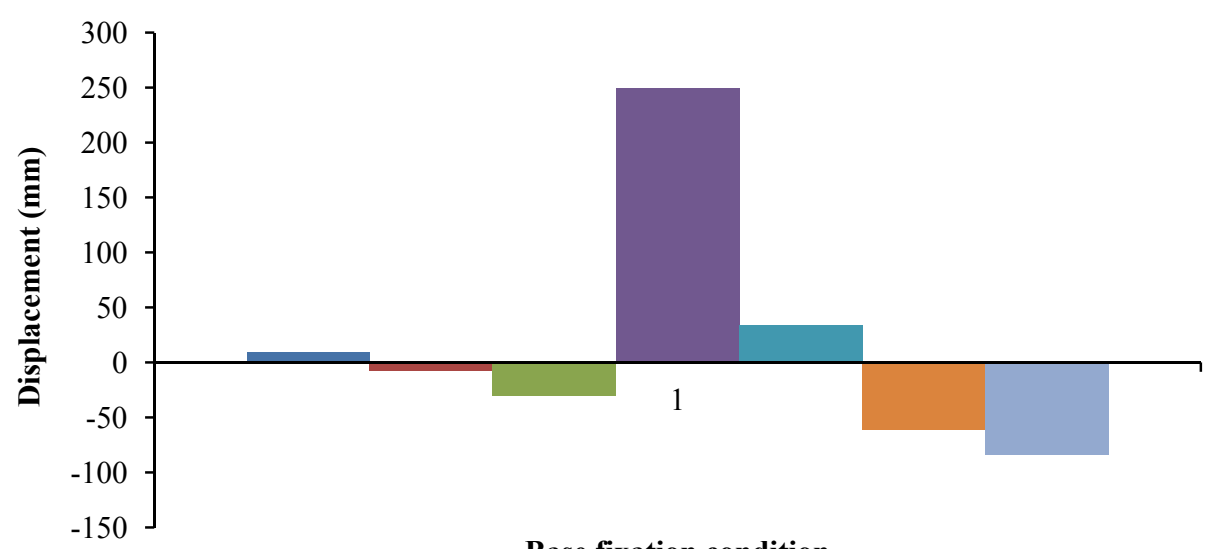

Base fixation condition

Fig. 9 Variation of frame displacement-dense gravel. 
Table 37 Values of excitation frequency for each case and their respective frequency ratio.

\begin{tabular}{llll}
\hline \multirow{2}{*}{ Case No. } & \multicolumn{2}{l}{ Excitation frequency } & Frequency ratio $(\mathrm{r})$ \\
\cline { 2 - 4 } & $f_{i}(\mathrm{~Hz})$ & $\begin{array}{l}\omega_{i} \\
\text { (radian/second) }\end{array}$ & 0.64 \\
\hline 1 & 0.027 & 0.17 & 0.79 \\
2 & 0.033 & 0.21 & 0.92 \\
3 & 0.039 & 0.245 & 1 \\
4 & 0.045 & 0.283 & 1.2 \\
5 & 0.051 & 0.32 & 1.35 \\
6 & 0.057 & 0.358 & 1.49 \\
\hline
\end{tabular}

which is the ratio between excitation frequencies and the first natural frequency of frame structure alone with fixed boundary condition as Eq. (15):

$$
\mathrm{r}=\frac{f_{i}}{f_{1}}
$$

Where,

$f_{i}=$ excitation frequency for case in $(\mathrm{Hz})$;

$f_{1}=$ the first natural frequency of frame with fixed boundary condition.

The Figs. 10-15 show the variation of the horizontal response of frame structure with frequency ratio (r) considering soil structure interaction effect.

It is well known from dynamic analysis that the response of a single degree of freedom structure to any excitation having frequency equal to the natural frequency of the structure will be in a resonance. For a multi degree of freedom structure, the effect of the excitation becomes a maximum when its frequency coincides with lowest frequency of the structure and usually in the design. The excitation frequency in the range of $0.5-1.5$ of the lowest natural frequency of the structure is avoided [6]. Therefore, this undesired range excitation frequency is considered in this study to determine the range of increase in the response of frame structure. As shown in Figs. 10-15, the maximum response is occurred when the frequency ratio (r) is between 0.64 and 1 . This difference in (r) is depended on the soil type.

\section{Conclusions}

The following conclusions can be drawn from the present study:

(1) The response of frame structure mainly depends on the first few vibration modes. Therefore, it is
Fixed case

Linear spring-case1

Linear spring-case 2

Linear spring-case 3

Linear spring-case 4

Linear spring-case5

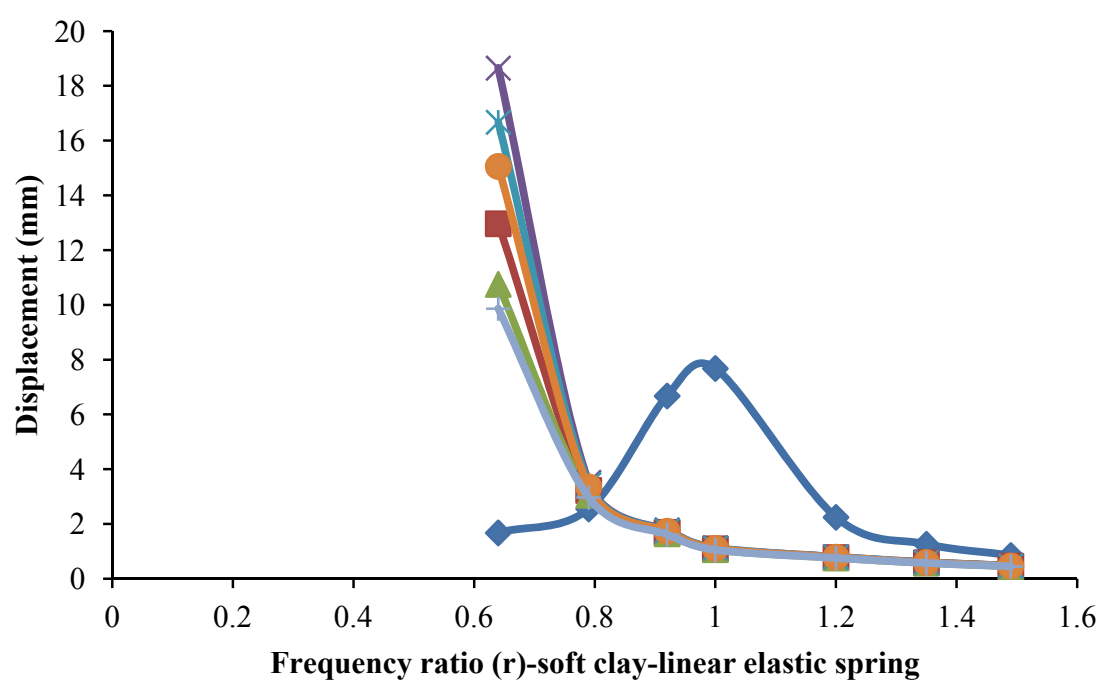

Frequency ratio (r)-soft clay-linear elastic spring

Fig. 10 Variation of response with frequency ratio. 
Fixed case

Halfspace1

Halfspace2

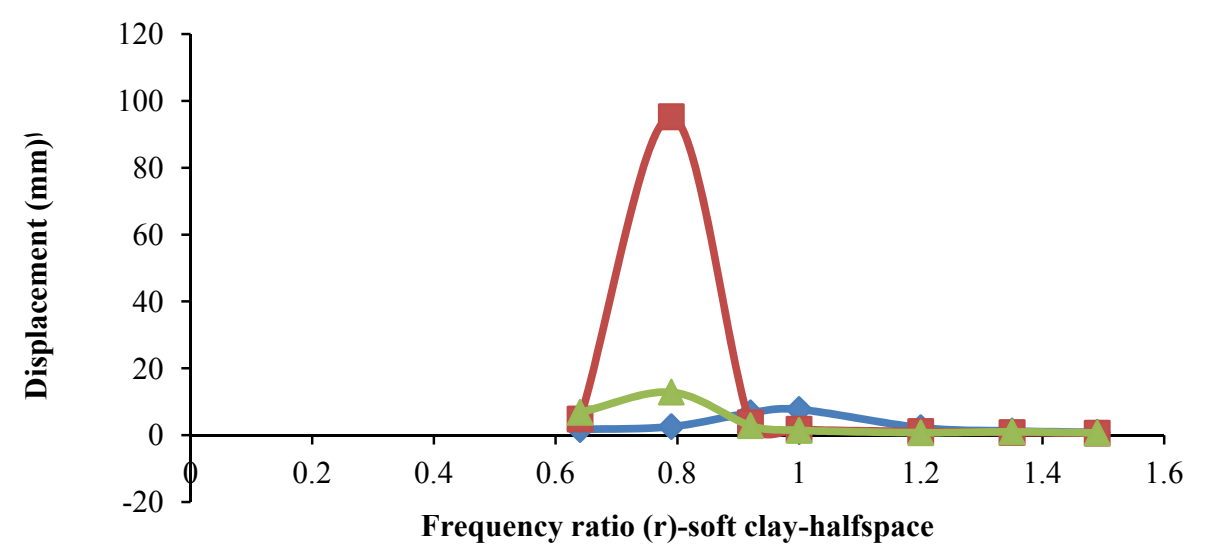

Fig. 11 Variation of response with frequency ratio.

Fixed case

Linear spring-case1

Linear spring-case 2

Linear spring-case 3

Linear spring-case 4

Linear spring-case 5

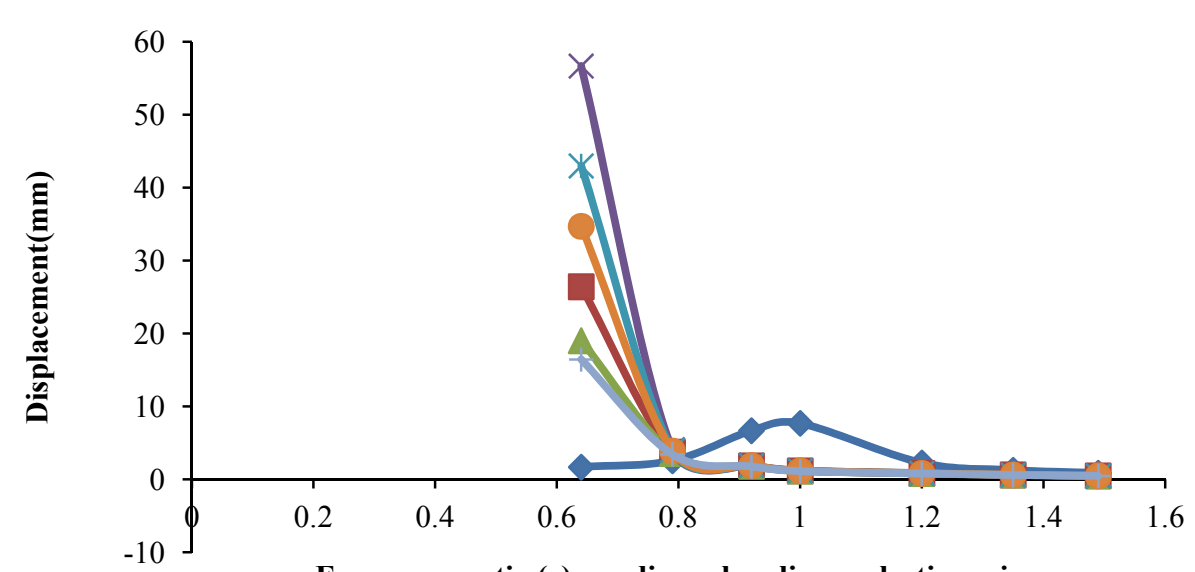

Frequency ratio (r)- medium clay- linear elastic spring

Fig. 12 Variation of response with frequency ratio.

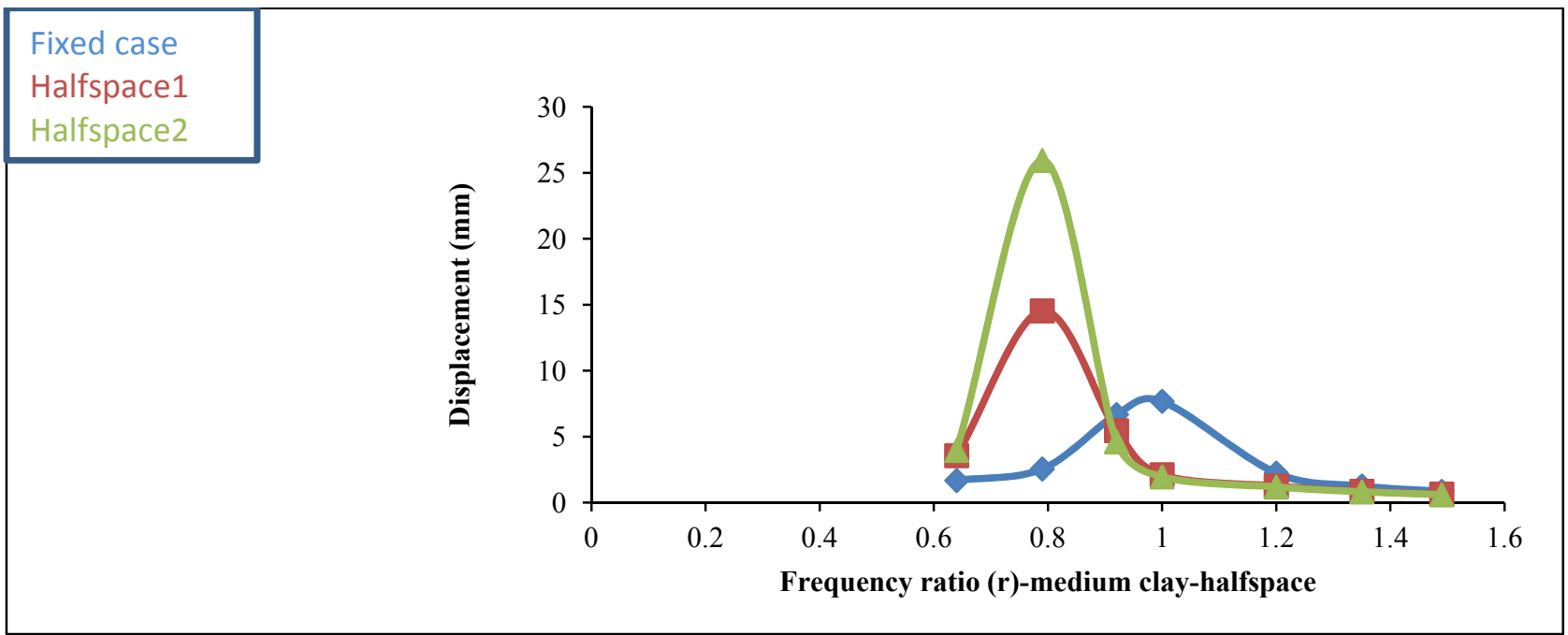

Fig. 13 Variation of response with frequency ratio. 
Fixed case

Linear spring-case 1

Linear spring-case 2

Linear spring-case 3

Linear spring-case4

Linear spring-case 5

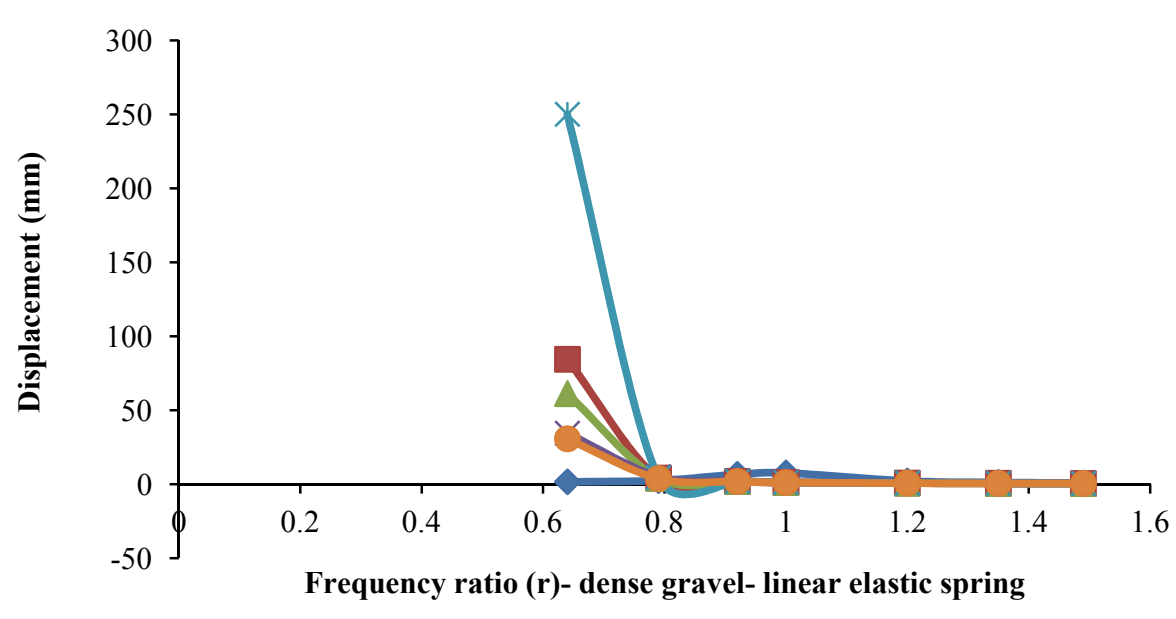

Fig. 14 Variation of response with frequency ratio.

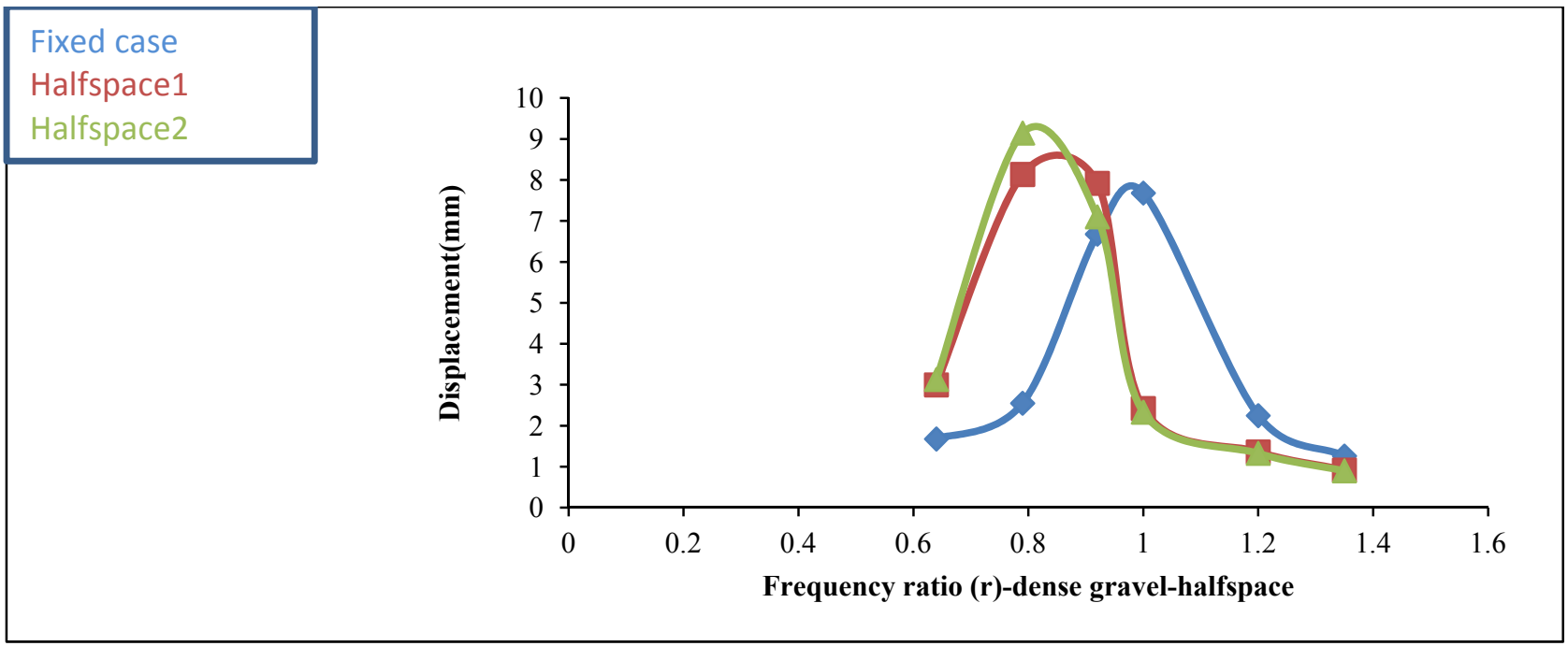

Fig. 15 Variation of response with frequency ratio.

important to determine accurately these vibration modes and the natural frequencies;

(2) Natural frequency for different base boundary conditions is sensitive for sway and less effect for bending, torsion and axial modes;

(3) The foundation flexibility increases the natural period of the platform;

(4) The harmonic response for the soil-structure interaction condition is higher than that for the rigidly supported base condition;

(5) The dynamic responses of the frame can very sensitive to the foundation model;

(6) The foundation flexibility results in a significant increase in the response of the frame structure;

(7) As the degree of the freedom increase, the response of the frame structure will increase;

(8) In the finite element idealization of soil-structure interaction problem such as the properties of linear spring and size of half space affect the analysis result;

(9) The responses of frame structure under dynamic load are higher in all cases of linear elastic spring as comparing with perfect bond cases;

(10) As the soil type change, the frequency ratio will be change and the soil-structure modeling has great effect on the frequency ratio; 
(11) As the soil type change, the response of frame structure will be change;

(12) The representation of soil sub-grade or stiffness will reflect on the response of structure under dynamic load.

\section{References}

[1] Raksha, J., and Khare, H. S. Chore. 2013. "Interaction of Building Frame with Pile." International Journal of Electrical, Electronics and Computer System (IJEECS) 1 (1): $2347-2820$.

[2] Hussein, H. A. 2003. "Dynamic Analysis of Offshore Structure Using Finite Element Method." M.Sc. thesis, Basrah University.

[3] Magade, S. B., and Patankar, J. P. "Effect of Soil Structure Interaction on the Dynamic Behavior of Buildings." IOSR Journal of Mechanical and Civil Engineering (IOSR-JMCE) 2278 (1684): 09-14.

[4] Samir, A. J. 2000. "Dynamic Analysis of Offshore Template Structures with Soil-Structure Interaction." Ph.D. thesis, Basrah University.

[5] Arya, S. C. O., Neill, M. W., and Pincus, G. 1979. Design of Structures and Foundations for Vibrating Machines. Houston: Gulf Publishing Company.

[6] Ahmed, R. Saber. 2010. "Effect of a Lateral Dynamically Loaded Pile on a Nearby Nulti-Story Building." M.Sc. thesis, Basrah University.

[7] Saad, Fahad, Resan. 2005. "Finite Element Analysis of
Circular Piles under Dynamic Load." M.Sc. thesis, Basrah University.

[8] Rao, S. S. 2004. The Finite Element Method in Engineering. USA: Elsevier Science and Technology.

[9] Yang, Y. B., and Hung, H. H. 2009. Wave Propagation for Train-Induced Vibrations. Singapore: World Scientific Publishing CO.

[10] Ronald, F. Scott. 1981. Foundation Analysis. California: California Institute of Technology.

[11] Joseph, E. Bowles. 1997. Foundation Analysis and Design, Fifth Edition. Singapore: McGraw-Hill Book Co.

[12] Jamshid, Sadrekarimi, and Maryam, Akbarzad. 2009. "Comparative Study of Methods of Determination of Coefficient of Subgrade Reaction." Electronic Journal of Geotechnical Engineering 14: 1-14.

[13] Silva, Pedro, F. "Seismic Evaluation of Full-Moment Connection CISS Piles/Foundation Systems." http://www.pwri.go.jp/eng/ujnr/tc/g/pdf/21/21-bf-7silva.p df.

[14] Mahmoud Yahyai, Masoud Mirtaheri Mahoutian, Amir Saedi Daryan, and Mohammad Amin Assareh. 2008. "Soil Structure Interaction between Two Adjacent Buildings under Earthquake Load." American J. of Engineering and Applied Sciences 1 (2): 121-125.

[15] Paz, M. 1980. Structural Dynamic Theory and Computation. New York: Van Nostrand Reinhold Company.

[16] Rafi, Mohammed, Qasim. 2011. "Dynamic Analysis of Fixed Offshore Platform to Wave Loading." M.Sc. thesis, Basrah University. 